PONTIFÍCIA UNIVERSIDADE CATÓLICA DO RIO DE JANEIRO

Brincar para Mudar: o Serious Play como Facilitador da Mudança Organizacional

\author{
Izabela Carvalho Rocha
}

Trabalho de Conclusão de Curso

CENTRO de CIÊNCIAS SOCIAIS - CCS

DePARTAMENTO de AdMINISTRAÇÃo

Graduação em Administração de Empresas 
Izabela Carvalho Rocha

\title{
Brincar para Mudar: o Serious Play como Facilitador da Mudança Organizacional
}

\author{
Trabalho de Conclusão de Curso
}

Trabalho de Conclusão de Curso, apresentado ao programa de graduação em Administração da PUC-Rio como requisito parcial para a obtenção do título de graduação em Administração.

Orientador: Francis Berenger

Rio de Janeiro

junho de 2019. 


\section{Resumo}

Rocha, Izabela Carvalho. O serious play como facilitador da mudança organizacional. Rio de Janeiro, 2019. 40 p. Trabalho de Conclusão de Curso - Departamento de Administração. Pontifícia Universidade Católica do Rio de Janeiro.

O trabalho pretende analisar em quais situações a utilização da abordagem do serious play pode auxiliar o processo de mudança organizacional. Para isso, utilizou-se como base de pesquisa a pesquisa exploratória com consultores e facilitadores do método do LEGO Serious Play e referenciais teóricos, que nortearam os resultados obtidos. Dessa forma, tornou-se possível sugerir interpretações e sugestões que as empresas poderão seguir a fim de atingir maior eficiência diante das dificuldades esperadas da mudança organizacional.

Palavras-chave: Mudança organizacional, Resistência à Mudança, Serious Play, LEGO Serious Play.

\section{Abstract}

Rocha, Izabela Carvalho. Serious Play as a facilitator of organizational change. Rio de Janeiro, 2019. 40 p. Trabalho de Conclusão de Curso Departamento de Administração. Pontifícia Universidade Católica do Rio de Janeiro.

This study aims to analyze in which situations the use of Serious Play method may assist the organizational change process. For this, the exploratory research with LEGO Serious Play method consultants and facilitators and also the theoretical reference was both used as base research to achieve the results. Therefore, it became possible to suggest interpretations and suggestions that the companies can follow in order to become more efficient beyond the expected difficulties of organization change.

Keywords: Organizational Change, Resistance to Change, Serious Play, LEGO Serious Plays. 


\section{Sumário}

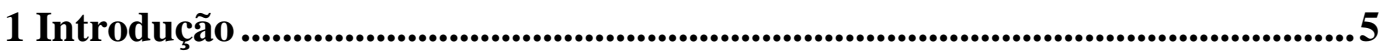

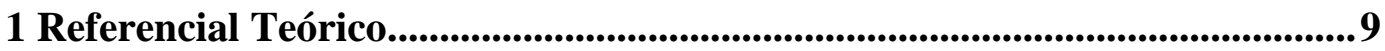

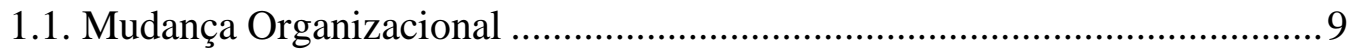

1.2. Da Resistência a Mudança Organizacional à Gestão da Mudança ............. 12

1.3. A Abordagem Serious Play.................................................................... 16

1.4. O Método do LEGO Serious Play........................................................... 19

2 Metodologia de Pesquisa .....................................................................................22

2.1. Tipos de Pesquisa e Método Utilizado...................................................... 23

2.2. Procedimentos e Instrumentos de Coleta de Dados Utilizados no Estudo . 24

2.3. Tratamento e Análise dos Dados Coletados para o Estudo ........................ 25

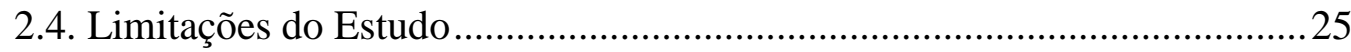

3 Apresentação e Análise dos Resultados ...................................................................26

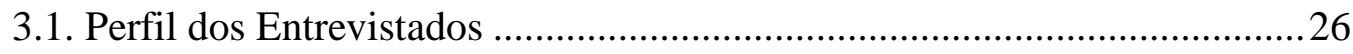

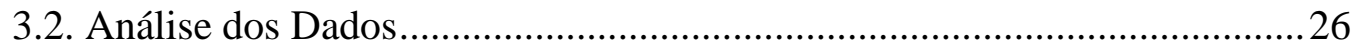

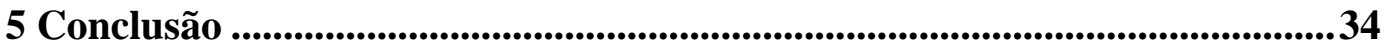

6 Referências Bibliográficas ..................................................................................36 


\section{Lista de Quadros}

Quadro 1: Definições de Mudança Organizacional

\section{Lista de figuras}

Figura 1: Como o Método LSP Cria Valor

\section{Lista de Tabelas}

Tabela 1: Perfil dos entrevistados facilitadores do LEGO Serious Play 


\section{Introdução}

Friedman (2005), em $O$ Mundo é Plano, analisa as consequências de um mundo globalizados, bem como a necessidade de mudança de países, indivíduos e companhias para se manterem competitivos no cenário global.

Sempre que a civilização passou por uma dessas revoluções técnicas disruptivas e dissonantes - como a introdução da prensa tipográfica por Gutenberg - o mundo inteiro mudou de maneira profunda. (FRIEDMAN, 2005, p. 44).

Dentro desse contexto, a alta velocidade de achatamento do mundo globalizado é uma das responsáveis pela criação de um novo cenário para atuação das empresas, conhecido como ambiente "VUCA".

O acrônimo configura quatro tipos diferentes de desafios - volatilidade, incertezas, complexidade e ambiguidade - que exigem diferentes respostas (BENEETT e LEMOINE, 2014). A volatilidade é experimentada quando uma ordem estabelecida é modificada ou substituída, fazendo com que eventos inesperados ocorram, enquanto eventos esperados não aconteçam (HORNEY e O’SHEA, 2015). A incerteza diz respeito ao estado em que há o desconhecimento do que está acontecendo ou do que vai acontecer, e inexistindo clareza se algo pode ser feito. Nota-se que, diante desses tempos voláteis, há a dificuldade do mapeamento de problemas e de eventos acontecidos no passado pelos líderes como estimativa de resultados futuros, o que torna a previsão extremamente díficil, assim como a tomada de decisão (HORNEY e O'SHEA, 2015). Complexidade, por sua vez, ocorre a partir da existência de muitas possíveis causas para qualquer evento, causa e efeito não são claros, uma vez que os desafios podem parecer difíceis de definir. A ambiguidade, diz respeito a ambiguidade, que ocorre quando existem múltiplos significados ou alternativas possíveis para uma determinada situação ou evento, fazendo com que certo ou errado, bom ou ruim não sejam auto-evidentes ou claras. Nesse sentido, importantes questionamentos põem dúvida a sobrevivência das organizações: Como as empresas vão lidar com esse novo ambiente? (HORNEY e O'SHEA 2015). 
O avanço tecnológico também é responsável por fomentar mudanças no ambiente em que as empresas estão inseridas. O imperativo tecnológico se confirma a medida que a tecnologia exerce efeitos determinantes em relação às diretrizes do desenvolvimentos humano em todas as suas nuances da sociedade, da economia e da política, influenciando também o comportamento das organizações. É confirmar, neste contexto, a importante influência transformadora que as tecnologias exercem nos ambientes e processos que são implementados. Nesse sentido, as empresas são destinadas a se adaptarem à nova realidade, fazendo com que a transformação para o digital fosse parte do êxito deste processo. Dominar as novas regras de um mercado balizado pela tecnologia não é assumir apenas um papel estratégico, mas também desenvolver vantagem competitiva capaz de redefinir modelos de negócios. É diante deste cenário, portanto, que instabilidade começa a fazer parte da realidade das empresas, fazendo com que ser bem-sucedido nesse ambiente seja pontuado por uma transformação em como uma organização opera, em como ela pensa sobre si mesma e é conduzida (HORNEY e O'SHEA, 2015). É no sentido de não conseguir se transformar ou se adaptar que reside a fragilidade de gestão no contexto atual.

As organizações começam a buscar novos paradigmas de gestão e modelos de negócios a fim de gerar adaptação aos novos moldes econômicos, fazendo com que o formato que são feitos os negócios se transformem profundamente. As empresas, assim, devem procurar ser focadas, rápidas e flexíveis, o que as posicionam para o sucesso em uma nova realidade (HORNEY E O'SHEA, 2015). De outro lado, as startups, que nos últimos 20 anos foram causa e consequência deste contexto apresentam características que as empresas tradicionais agora correm para desenvolver. Lembra-se que, por definição, uma startup é uma “instituição humana projetada para criar um produto ou serviço sob condições de extrema incerteza" (RIES, 2011, p. 12). São características típicas deste de negócios a estrutura extremamente enxuta, alta escalabilidade, baixos custos operacionais, alto desenvolvimento tecnológico e, principalmente, alto grau de adaptabilidade. Em outras palavras, são empresas que combinam estrategicamente agilidade e inovação. Em 2018, o país contava com 10.200 startups ativas, representando um crescimento de $20 \%$ em relação ao ano anterior (ABSTARTUPS, 2018). Neste período, cinco startups do Brasil tornaram-se "unicórnios", ou seja, atingiram o 
valor de mercado de 1 bilhão de dólares, sendo elas 99, PagSeguro, Nubank, Stone e Ifood. A tendência que, para 2019, um número ainda maior de empresas entre neste hall (IT MÍDIA, 2018).

Dessa forma, as incertezas do cenário atual somadas ao crescimento de modelos de negócios mais ágeis e escaláveis, resultam em, respectivamente, possível ameaça para as empresas tradicionais. Neste sentido, o caminho mais estratégico para sobreviver a tal realidade é o de se transformar, no que Ries (2017) conceitua como empresa moderna. Empresa moderna é aquela que se baseia em impacto prolongado mediante inovação contínua, se concentra em resultados a longo prazo, deixando para trás seus concorrentes. Ainda segundo o autor, a gestão moderna, requer uma filosofia de longo prazo, unida à experimentação extremamente rápida, descobrindo estratégias que apoiam a visão à longo prazo.

A transformação do modelo tradicional para o moderno, todavia, encontra barreiras dentro da própria organização para que tais mudanças ocorram. Para Magaldi e Salibi Neto (2018), a resistência cultural à mudança, em geral, está no cerne da questão. Ainda sob a opinião do autor, líderes adotam uma visão racional ao concluírem que a transformação em suas organizações é mandatória, fazendo com que se dediquem principalmente em modificar as estratégias corporativas ao adotar uma nova perspectiva para o negócio. No entanto, quando este processo não acontece em consonância com uma mudança genuína de cultura, esta tende ao fracasso.

Neste ponto, é necessário questionar-se não só a respeito das barreiras relacionadas às transformações de empresas tradicionais em modernas, mas também na transformação da cultura tradicional em cultura da inovação. Sabe-se que um caminho estratégico para tal fim, é motivar e incluir pessoas em um aspecto crucial em qualquer processo de mudança, criando a necessidade de métodos e ferramentas que abrangem isso (DEMPSEY et al., 2014). A gestão da mudança, nesse sentido, é uma forma de responder aos problemas derivados do contexto atual, transformando-os em oportunidades a partir da busca por saídas estratégicas (KOTTER, 1999).

A abordagem do Serious Play, neste contexto, é apresentada como uma das possíveis facilitadoras para a quebra de barreiras que impedem a adaptação cultural 
ao novo contexto. Sabe-se que tal metodologia funciona como um modo de atividade que se baseia na imaginação, integrando dimensões cognitivas, sociais e emocionais e traz, intencionalmente, benefícios emergentes do brincar para os desafios organizacionais (ROOS et al., 2014). O tema encontra espaço dentro das empresas ao ser patrocinado por uma tendência social de comportamento, em que a cultura lúdica e a economia de experiência, percebem o "brincar" não apenas como caracterização do tempo de lazer, mas também para domínios que costumavam ser mais "sérios", como é o trabalho em organizações (KUEPERS, 2017). Sendo assim, sua influência positiva no alcance das metas e das estratégias, encontra sua justificativa em sua abordagem que não diz respeito apenas a liberação da criatividade das pessoas, mas também a incluí-las de forma ativa nos processos criativos de solução de problemas, construindo, assim, a identidade com a solução envolvida (DEMPSEY et al., 2014).

O Serious Play em tradução livre significa "brincar sério", uma vez que é através da ótica de jogo que se consegue alcançar seus maiores objetivos: despertar a motivação em seu nível emocional. É, nesse sentido, que a abordagem pode ser considerada uma forma de causar o engajamento individual e, consequentemente, organizacional para qualquer fim. Neste sentido, cria-se o principal questionamento deste artigo: como o serious play pode ajudar no processo de facilitação na mudança organizacional?

Dessa forma, intenciona-se que a contribuição deste artigo esteja presente dentro do contexto de mudança organizacional, explorando a abordagem do Serious Play como eficaz no combate contra a resistência, facilitando tal processo. O trabalho é dividido em seis capítulos, sendo eles: Introdução, Referencial Teórico, Metodologia da Pesquisa, Apresentação e Análise dos Resultados, Conclusão e Referências Bibliográficas. A metodologia utilizada foi a pesquisa exploratória descritiva de natureza qualitativa, trantando-se de um estudo semiestruturado, não positivista. 


\section{Referencial Teórico}

\subsection{Mudança Organizacional}

A transformação digital tem sido responsável, junto ao processo iminente de globalização, por orquestrar a nova realidade dos dias atuais. Esse movimento pode-se traduzir como a velocidade exponencial e às mudanças disruptivas que ocorrem na sociedade e que são patrocinadas e impulsionadas pela rápida adoção da tecnologia (SILVA, 2018). Diante deste cenário, como parte sensível às evoluções sociais, as organizações são alvo da necessidade de mudança, que, muitas vezes, começa a partir do rompimento dos paradigmas empresariais.

Para Joel Baker, segundo Chiavenato (1996, p. 260), entende-se como paradigma o estabelecimento de regras a partir de regras e regulamentos. Ainda segundo o autor:

A vida das pessoas e das organizações é regrada e delimitada por determinados paradigmas. Estes paradigmas definem as fronteiras entre o certo e o errado, entre o que é verdadeiro e o que é falso, entre o que se deve fazer e o que não se deve fazer. Na verdade, um paradigma estabelece um corredor de pensamentos no qual este fica bitolado ao que existe dentro das faixas e dos limites permitidos.

Dentro da ótica corporativa, portanto, os paradigmas funcionam como balizadores da construção do posicionamento das empresas, limitando sua missão, sua visão, seus valores, seu desenho organizacional, suas metas e seus objetivos, assim como todos os outros fatores que moldam sua personalidade e cultura organizacionais (DOS SANTOS, 2005).

Dessa forma, esse são responsáveis pela definição de comportamento dos colaboradores e estilo de gestão, o que justifica o porquê do processo de mudança organizacional, muitas vezes, ocasionar a quebra de alguns paradigmas organizacionais. Nesse sentido, planejar e executar mudanças em uma organização passa necessariamente pela transformação de paradigmas, entendendo que as pessoas deles fazem parte. Ou seja, o "mudar" na organização diz respeito à mudança do comportamento e da atitude das pessoas e adequá-las aos novos 
paradigmas necessários às novas e atuais condições de sobrevivência da empresa (DOS SANTOS, 2005).

Muitas são as definições acerca da mudança organizacional. Para este artigo, destaca-se a de Nadler, Shaw e Walton (1995), que entende seu conceito como respostas das organizações às transformações ocorridas no ambiente, objetivando manter a congruência entre os componentes organizacionais, sendo esses trabalhos, pessoas, estrutura e cultura. A fim de comparação e complementação, apresenta-se também a visão de Lima e Bressan (2003), defendendo que a mudança como qualquer alteração implementada nos componentes organizacionais como um todo, ou nas relações com seu ambiente, podendo ser ou não planejada e gerando consequências relevantes, positivas e negativas para os resultados organizacionais ou para sua sobrevivência. Bressan (2004), traz um compilado de definições de renomados autores sobre mudança organizacional, o que faz com que seja perceptível a observação das similaridades e diferenças em relação a sua descrição.

Quadro 1: Definições de Mudança Organizacional.

\begin{tabular}{|c|c|}
\hline Definiçōes de Mudança Organizacional & Autor \\
\hline $\begin{array}{l}\text { É qualquer alteração, planejada ou não, ocorrida na organização, decorrente de } \\
\text { fatores internos e/ou externos à organização que traz algum impacto nos } \\
\text { resultados e/ou nas relações entre as pessoas no trabalho. }\end{array}$ & Bruno-Faria (2000) \\
\hline $\begin{array}{l}\text { Qualquer transformação de natureza estrutural, estratégica, cultural, tecnológica, } \\
\text { humana ou de outro componente, capaz de gerar impacto em partes ou no } \\
\text { conjunto da organização. }\end{array}$ & Wood Jr (2000) \\
\hline $\begin{array}{l}\text { Resposta da organização às transformações que vigoram no ambiente, com o } \\
\text { intuito de manter a congruência entre os componentes organizacionais (trabalho, } \\
\text { pessoas, arranjos/estrutura e cultura) }\end{array}$ & $\begin{array}{l}\text { Nadler, Shaw, Walton } \\
\text { e cols. (1995) }\end{array}$ \\
\hline $\begin{array}{l}\text { É um acontecimento temporal estritamente relacionado a uma lógica, ou ponto } \\
\text { de vista individual, que possibilita às pessoas pensarem e falarem sobre a } \\
\text { mudança que percebem. }\end{array}$ & Ford e Ford (1995) \\
\hline $\begin{array}{l}\text { Conjunto de teorias, valores, estratégias e técnicas cientificamente embasadas } \\
\text { objetivando mudança planejada do ambiente de trabalho com o objetivo de } \\
\text { elevar o desenvolvimento individual e o desempenho organizacional. }\end{array}$ & $\begin{array}{l}\text { Porras e Robertson } \\
(1992)\end{array}$ \\
\hline $\begin{array}{l}\text { Alteração significativa articulada, planejada e operacionalizada por pessoal } \\
\text { interno ou externo à organização, que tenha o apoio e supervisão da } \\
\text { administração superior, e atinja integradamente os componentes de cunho } \\
\text { comportamental, estrutural, tecnológico e estratégico. }\end{array}$ & Araújo (1982) \\
\hline
\end{tabular}

Fonte: BRESSAN (2004, p.3).

A literatura se divide em três principais vertentes sobre o que se diz respeito à mudança organizacional, o que obedece a um comportamento evolutivo. A primeira delas, que utiliza o modelo de Lewin e Gold (1999) como norte, defende 
um ciclo composto por descongelamento, mudança e recongelamento. O estágio inicial de descongelamento se dá quando se é percebido o estágio atual da organização como indesejável, o que desperta o sentimento de necessidade de mudança. Em seguida, a empresa entra no estágio em que a mudança, de fato, ocorre. Neste ponto, são implementadas tentativas de transformação a fim de adaptar a nova situação ao ambiente, adequando-a para o trabalho e para as pessoas. Já no terceiro e último estágio, é experimentado o processo de recongelamento, que é caracterizado pelo momento em que o que foi mudado passa a ser incorporado na rotina organizacional e nos pensamentos dos colaboradores. É, neste ponto, que há a conclusão do processo, uma vez que a mudança é incorporada e a empresa começa a se comportar em relação a nova realidade de forma integral (LEWIN E GOLD, 1999).

A segunda vertente teórica apresenta a síntese das pesquisas relacionadas com os aspectos ligados aos níveis organizacionais e todos os fatores que influenciam na mudança organizacional, como missão e estratégia, por exemplo (KOTTER, 1995). Por sua vez, a última corrente teórica defende a mudança organizacional a partir de estudos que objetivam compreender o comportamento, os valores, as motivações individuais, as necessidades e suas influência para um bom desempenho dos esforços para a mudança (MARQUES, 2012). Para este artigo, considerou-se ser a terceira vertente como mais adequada para a formulação deste artigo, uma vez que se valoriza o colaborador como parte importante e insubstituível dentro do processo de mudança organizacional, ou seja, acredita-se que a motivação individual frente à mudança é diretamente proporcional ao sucesso, como anteriormente defendido.

Para Wood Jr., Curado e Campos (1994), a mudança organizacional pode ser classificada em três tipos diferentes: a) em relação à sua natureza, ou seja, relacionada a personalidade e cultura organizacionais, como missão, visão e valores, etc; b) quanto à relação da empresa com o ambiente, entendendo a sua capacidade de reação ativa ou passiva em resposta ao ambiente e, c) em relação à implementação, podendo ser classificada em reeducativa, coercitiva e racional. 
Também nesse sentido e segundo Robbins (2003), o processo de mudança organizacional pode efetivamente objetivar inúmeros aspectos que, essencialmente, estão relacionados a quatro categorias.

a) Estrutura: quando as mudanças são operadas na estrutura da organização, redesenhando e adaptando, por exemplo, departamentos, coordenação, centros de controle e perfil de tarefas.

b) Tecnologia: quando as mudanças são operadas em relação a incorporação de tecnologias, que podem envolver a compra de novos equipamentos, ferramentas, métodos de operação, além da introdução da tecnologia de informação, sistemas de gestão de informação e de dados, por exemplo.

c) Espaço Físico: quando as mudanças operadas são relacionadas ao espaço físico dentro de uma organização, não exercendo um impacto significativo na performance organizacional (STEELE, 1986).

d) Pessoas: quando as mudanças são operadas a nível comportamental, incitando a mudança cultural e de atitudes das pessoas e grupos existentes na organização.

\subsection{Da Resistência a Mudança Organizacional à Gestão da Mudança}

Para Chiavenato (2016), "Mudança é a passagem de um estado para o outro. É a transição de uma situação para outra diferente. Mudança representa transformação, perturbação, interrupção, fratura". Dessa forma, entende-se, que dentro de tal contexto, o processo de mudança organizacional é responsável por causar incertezas que são podem afetar psicologicamente os indivíduos, provocando medo e, dessa forma, gerando resistência, constituindo uma das principais barreiras para o sucesso das mudanças dentro de organizações (FREIRES et al., 2014).

A resistência à mudança é definida por alguns teóricos como multidimensional, sendo a resposta à mudança que inclui dimensões cognitivas, afetivas e comportamentais (BORTOLOTTI, 2010; OREG, 2006; PIDERIT, 2000). A dimensão afetiva é relacionada ao sentimento do indivíduo diante do processo de mudança, enquanto a cognitiva é responsável por seus pensamentos. A dimensão 
comportamental, por sua vez, foca nos comportamentos, atitudes e intenções diante da mudança.

Oreg (2006), apresentou, baseado na proposta de Piderit (2000), um modelo empírico global de resistência à mudança. O objetivo da pesquisa era a relação entre personalidade, contexto organizacional e a resistência que podem afetar positiva ou negativamente os resultados no trabalho (FREIRES et al., 2014). Nesse sentido, entendeu-se que as pessoas se diferem umas das outras por meio da predisposição interna e individual para resistir ou incorporar a mudança. Tais diferenças conseguem provisionar atitudes pessoas em relação a mudanças específicas, tanto voluntárias, quanto impostas. Neste contexto, portanto, a resistência à mudança consegue ser conceituada como um traço de personalidade estável, entendendo que, segundos os mesmos autores, "as pessoas que têm esta disposição são menos propensas a incorporar as mudanças voluntariamente e, quando estas são impostas, experimentam reações emocionais negativas, como ansiedade, raiva e medo". Entretanto, quanto maior for o impacto trazido pelas mudanças, maiores serão as chances de encontrar perfis que não se sintam adaptados, potencializando a resistência. São considerados comportamentos resistentes: tendência a culpar outros, inércia, omissão, dificuldade para enfrentar os desafios da vida e falta de controle sobre seu próprio destino (BOVEY E HEDE, 2001).

Por outro lado, a predisposição individual não é uma variável única que determina o grau de resistência às mudanças organizacionais, uma vez que também são presentes fatores associados à própria organização. A percepção que os membros da organização possuem sobre a eficiência da gestão da mudança também é considerada fator chave para a ocorrência ou não de comportamentos resistentes. Os colaboradores conseguem qualificar ou desqualificar a implementação da mudança ao perceber a presença ou a ausência de situações como: a) se o processo está sendo conduzido por profissionais experientes e com expertise no assunto; b) se há consistência das alterações propostas com os objetivos e metas das organizações; c) se há o apoio e a promoção das promoções necessárias diante do processo, sendo essas realizadas pelos líderes, gerentes e demais colaboradores (MARQUES et al., 2005). Neste sentido, o julgamento do colaborador sobre o quão capaz é a organização de realizar a mudança com sucesso, assim como a percepção 
clara de seus benefícios, podem direcionar o comportamento do indivíduo para cooperação ou não diante da mudança (Marques et al., 2014).

Dentro do contexto organizacional, as resistências ao processo de mudança deverão ser contornadas a fim de possibilitar seu sucesso e diminuir as chances de seu fracasso. Segundo os autores Tidd, Bessant, Pavitt (2005), a resistência poderá ser contornar ao criar um clima aberto, no qual anseios e preocupações individuais possam ser expressos e as idéias e conhecimentos mantidos dentro da organização possam ser usados para um efeito positivo. Mais uma vez, isso envolve gerar um senso de "propriedade" do projeto e compromisso com as metas compartilhadas de toda a organização - em vez de um clima "nós e eles".

E, ainda segundo Silva (2005), as empresas bem-sucedidas em programas de mudança organizacional são aquelas que comunicam intensamente, de forma efetiva, a seu pessoal dois fatos fundamentais. O primeiro é a posição que a empresa alcançou no mercado com seus métodos e processos de trabalho e por que razão ela não pode permanecer nessa situação que lhe traz perdas e prejuízos. O segundo é onde a empresa pretende chegar com a mudança e qual o papel que as pessoas terão que desempenhar para que a empresa conquiste seus objetivos.

Nesse sentido, confirma-se, novamente, que envolver as pessoas no processo é fator determinante para evitar resistência e diminuir as chances de insucesso diante deste tipo de processo organizacional.

Ainda de acordo com o posicionamento do autor, a participação e o envolvimento são também aspectos fundamentais para o êxito da gestão da mudança. A resistência é amenizada com um esforço participativo da mudança, ou seja, é necessário abrir espaço para escutar diferentes opiniões e pontos de vistas dos colaboradores, colocando-os como sujeitos ativos e não passivos dentro do processo. Dessa forma, a causa passa a ser compartilhada, o que é capaz de engajar e motivar diferentes níveis hierárquicos em prol do mesmo objetivo.

A gestão da mudança, nesse aspecto, é responsável pela tentativa de transformação dos desafios gerados pela necessidade de mudança, sendo um deles a resistência, em verdadeiras oportunidades (KOTTER, 1999). Segundo Anderson e Anderson (2001), a gestão da mudança deverá ter, em seu escopo, três principais 
elementos, que são conteúdo, pessoas e processos. O conteúdo é baseado no objeto de mudança, que pode ser desde a estratégia até a estrutura organizacional, por exemplo. Já as pessoas dizem respeito aos comportamentos, sensações, emoções e demais reações dos seres humanos que estão sendo impactados direto ou indiretamente pela mudança. Por sua vez, os processos correspondem ao como as mudanças no conteúdo e/ou nas pessoas são planejadas, desenhadas, executadas e implementadas. Dessa forma, a gestão da mudança, deverá se basear no entendimento da execução dos processos de mudança, mapeando e identificando o que precisa ser mudado e definindo como esta será realizada na prática (HAYES, 2002).

Para Duck (1999) a gestão da mudança está compreendida como gerenciamento da integração entre pessoas que assumem a liderança diante do processo de mudança, assim como todas aquelas que são impactadas por ela. Além disso, também é papel da gestão da mudança o desenvolvimento de um ambiente organizacional que esteja preparado para a mudança, assim como a administração das questões emocionais inerentes ao processo a fim de gerar satisfação a todos os colaboradores.

A American Productivity Quality Center (1997) examinou, nesse sentido, as melhores práticas durante o processo de mudança em empresas americanas, resultando em cinco elementos-chave que são responsáveis pelo seu sucesso. São elas:

a) comprometimento e participação ativa do líder.

b) mudança fundamental na cultura organizacional.

c) envolvimento ativo dos colaboradores.

d) métricas e comunicação efetivas na organização.

e) alinhamento dos recursos humanos com as metas e objetivos da organização. 
Ainda segundo o estudo, as mudanças organizacionais significativas podem demandar de grande esforço para mobilizar toda a organização quanto a sua necessidade, nomeando um líder para comandar tal processo e mobilizar o restante dos indivíduos, sendo este auxiliado pela eficiência de uma comunicação clara.

Em relação a comunicação, segundo Reis (2004), as afirmações acerca dos estudos que a relacionam com a mudança organizacional, são divididas em três pontos diferentes. A primeira diz respeito a ausência da comunicação nos processos de mudança; a segunda, é a afirmação que a comunicação auxilia no processo de mudança e a terceira é de que comunicação é diretamente proporcional ao sucesso do processo de mudança organizacional. As técnicas tradicionais de comunicação, como aquelas que são tradicionalmente utilizadas para divulgar a exemplo de jornais internos, murais e vídeos institucionais são eficientes no suporte a gestão, mas não incitam a reflexão sobre o trabalho e o comportamento. Além disso, tais meios de comunicação não são responsáveis por despertar a necessidade de questionamentos de forma profunda, os mesmos que podem motivar a aprendizagem e produzir mudança (ARGYRIS E SCHON, 1996).

Muitas vezes, as empresas encontram dificuldade de conduzir esse processo. Dessa forma, importância de terceiros como agentes no processo de formulação da estratégia perante a mudança organizacional, sejam consultores ou parceiros, é discutida por Whittington, uma vez que possuem a capacidade de orientar os gestores e colaboradores, auxiliando na capacidade de diagnosticar problemas, além de gerar e implementar soluções (WHITTINGTON, 2006).

\subsection{A Abordagem Serious Play}

É dentro do sentido de engajamento, envolvimento, motivação e criatividade que o Serious Play passa a ser entendido como abordagem organizacional. A separação das duas palavras que compõem tal conceito, consegue sugerir com mais facilidade a sua definição. O Play (ou jogo, em português), (HUIZINGA, 1971, p. 41), é "uma atividade completamente lúdica quando é: a) totalmente absorvente; b) motivada intrinsecamente; c) inclui elementos de incerteza ou surpresa e d) envolve o senso de ilusão ou exagero”. Já o Serious (ou 
sério, em português), é entendido como a soma de um propósito explícito a um jogo. Segundo Kristiansen e Rasmussen (2014, p. 45):

É tratar um assunto real com participantes ao redor de uma mesa por meio do engajamento deles, desbloqueio de seus conhecimentos e quebra do pensamento convencional'. O autor ainda explica que 'o jogo surge de uma propensão inata de imitar, aliviar o estresse acumulado ou preparar e exercitar para questões funcionais mais sérias'.

O jogo, nesse sentido, ao mesmo tempo que é uma resposta natural do indivíduo a desafios, também é responsável pelo desenvolvimento, adaptação, resiliência e percepção de oportunidades (KRISTIANSEN E RASMUSSEN, 2014), características comportamentais cada vez mais demandadas pelas empresas atualmente. É, portanto, nesse sentido, que a abordagem encontra sinergia como possível forma de facilitar o processo de mudança organizacional.

Ainda segundo Kristiansen e Rasmussen (2014), o Serious Play é definido a partir de três características-chave:

a) é uma reunião intencional para utilização da imaginação.

b) é um processo de exploração e preparação, não implementação.

c) segue um conjunto específico de regras ou linguagem.

Por mais que os benefícios atrelados a aplicação de jogos para a efetividade da resolução de temáticas reais, muito ainda se discute em relação a tendência do senso comum em definir o jogo como oposto do trabalho, o que ocasiona pensamentos céticos quanto ao fato de que o jogo é uma caracterização válida para um comportamento adulto (RIEBER et al., 1998). Entretanto, Blanchard (1995) descreve um modelo derivado da antropologia que consegue demonstrar a relação mais clara e precisa sobre o brincar e o trabalho. Este é entendido a partir de duas dimensões, o prazer e o propósito, sendo o brincar e o trabalho construções ortogonais. Nesse sentido, trabalho e lazer estão em lados extremos, fazendo com que trabalho esteja sempre relacionado com um objetivo proposital, enquanto o lazer não. 
Dessa forma, os quadrantes que são apresentados no modelo de Blanchard (1995) representam toda a gama de atividades humanas, sendo esses:

a) Quadrante A: definido como trabalho lúdico, que corresponde a ser pago por um trabalho que também é satisfatório e recompensador.

b) Quadrante C: definido como trabalho não-lúdico, diz respeito a tipos de trabalho que não são agradáveis, mas que são realizados por obrigação ou necessidade financeira.

c) Quadrante B: definido como jogar pelo lazer, é geralmente alheio ao trabalho, uma vez que inclui atividades que normalmente dedicam deliberado esforço, por longo período de tempo e que são interpretados como passatempos sérios e distrações.

d) Quadrante D: definido como não-lazer, inclui os momentos que comumente são definidos como lazer, mas que só se realizam em momentos de tédio, insatisfação e ócio.

Nesse sentido, o modelo defende que as metas para o trabalho (contidas nos quadrantes A e C) são externas ao indivíduo, enquanto as metas para o lazer (contidas nos quadrantes B e D) são internas. A pessoa que atinge a máxima satisfação, ou seja, aquela que transita entre os quadrantes A e B conjuntamente, também pode ser compreendida pela Teoria do Flow, desenvolvida por Csikszentmihalyi (1990). A literatura diz respeito a um estado de felicidade e satisfação que consegue ser atingido pelo indivíduo, desenvolvendo um padrão conhecido como "experiência ótima", que é definido como "uma atividade realizada sem expectativa de algum benefício futuro, mas porque realizá-la é a própria recompensa" (CSIKSZENTMIHALYI, 1990). O Flow, dessa forma, é considerado o equilíbrio harmônico que é responsável pelo alto grau de satisfação durante o desempenho de uma atividade. Nesse sentido, a autora elenca algumas características que estão presentes durante o estado de Flow. Sendo essas:

a) foco e concentração: envolvimento total com a atividade.

a) êxtase: um sentimento de estar longe da realidade diária. 
c) clareza/feedback: diz respeito ao engajamento na atividade, que ocorre de maneira intensa, dado que o retorno rápido, de acordo com o que está sendo realizado, torne-se um requisito para continuar com a atividade de forma prazerosa e satisfatória.

d) habilidades: as atividades são constituídas de desafios a serem realizados, contudo é necessário que o indivíduo apresente aptidão apropriada para realizá-la.

e) perda da sensação do tempo: o foco na atividade promove a sensação de estar além da dimensão temporal.

Dessa forma, o Flow, é existente quando há o equilíbrio entre a competência individual e o desafio proposto. Nesse sentido, desafios extremamentes difíceis, que superem a competência pessoal, geram ansiedade. Da mesma forma, desafios extremamentes fáceis geram tédio. É na harmonia entre os dois fatores que criam o melhor momento da experiência, sendo exemplificado pelo momento em que são superadas expectativas e habilidades em prol de um resultado (KRISTIANSEN e RASMUSSEN, 2014). Diante deste cenário, a proposta do Serious Play é conseguir patrocinar e conduzir o estado do Flow para que indivíduos participantes consigam alcançar alto nível de engajamento para a resolução de um problema real, identificando oportunidades e ressignificando conhecimentos. Tal característica de comportamento mostra-se bastante interessante para empresas que buscam metodologias alternativas para geração de soluções e demais questões que permeiam a necessidade de mudança trazida pelo contexto atual.

\subsection{O Método do LEGO Serious Play}

O método do LEGO Serious Play é uma das formas encontradas para regular e canalizar a sistemática dos benefícios apresentados no item anterior, utilizando os blocos do Lego junto aos conceitos do brincar trazido pelo Serious Play. O LSP se originou a partir das necessidades que Kjeld Kirk Kristiansen, proprietário e então CEO da LEGO, enfrentava com as incertas perspectivas em relação ao futuro da companhia. Em 1996, se juntou com os professores Bart Victor e Johan Ross da 
IMD Business School, na Suíça, onde perceberam em conjunto as fragilidades dos métodos tradicionais para o desenvolvimento de estratégias. Foi nesse sentido que o gestor concordou em financiar uma pesquisa que daria vida ao LEGO Serious Play, que tinha como objetivo incentivar as pessoas a expressarem de melhor forma o seu potencial (KRISTIANSEN e RASMUSSEN, 2014).

Nesse sentido, o método pode ser definido como um workshop facilitado, em que participantes respondem aos desafios e questões propostas a partir da construção de modelos simbólicos e metafóricos com peças do LEGO, sendo esses apresentados aos demais participantes (DEMPSEY et al., 2014). Formam, então, valores básicos da aplicação do LSP diretrizes como "a resposta está no sistema", "todos necessariamente precisam expressar suas opiniões" e "não há uma resposta certa ou um ganhador".

Em uma aplicação convencional do método, há o pedido, em primeiro momento, da construção da percepção de um problema em particular. Diante do processo criativo e espontâneo de construção, os participantes materializam seus modelos, que posteriormente são explicados, através de storytelling, para os demais. Ressalta-se que as perguntas poderão ser realizadas, mas que os participantes devem respeitar o modelo apresentado e o seu significado. Nesse sentido, os modelos individuais podem ser usados para construir um modelo compartilhado, desenhando conexões e criando um cenário com os chamados "agentes externos", ou seja, opiniões alheias ao do próprio indivíduo. Em uma reflexão final, o grupo cria insights sobre o que foi criado e como o que foi apresentado poderá contribuir para a realidade dos fatos. Dessa forma, entende-se que todo modelo poderá servir de base para jogar, para analisar cenários particulares e, principalmente, extrair princípios orientadores (KRISTIANSEN et al., 2009).

Os participantes, dentro desta dinâmica, são capazes de interagir em um ambiente livre de julgamentos, de livre pensamento e lúdico, podendo desenvolver o entendimento comum, a geração de soluções e ideias criativas (KRISTIANSEN et al., 2009), baseadas em quatro construções principais:

a) A importância e relevância do brincar como forma de aprender através da exploração e do storytelling. Questões relacionadas com vínculo social, expressão emocional, desenvolvimento cognitivo e competição construtiva 
são trabalhadas e exploradas diante da utilização do método, o que, mais uma vez, confirma o propósito de brincadeira séria e baseadas em problemáticas reais. Para brincar, as peças do LEGO são associadas a pessoas e objetos já conhecidos pelos participantes. Além disso, é durante o storytelling que são evidenciados a cultura e pertencimento ao grupo, dentre outros fatores.

b) O Construtivismo e o Construcionismo. O primeiro, idealizado e defendido por Jean Piaget, defende o conceito de que pessoas constroem estruturas (e modelos) baseados nas experiências que já vivenciaram já o segundo, criado por Seymour Papert, diz respeito a relação do engajamento com o processo de construção. Para ele, quanto mais engajadas e parte dos processos os indivíduos se perceberem, maior será seu grau de aprendizado.

c) A conexão mão-mente como um caminho para o pensamento criativo e expressivo. A partir do pensamento que não se é conscientemente conhecido a maior parte do que se tem conhecimento, as mãos, nesse sentido, são responsáveis por materializar pensamentos que geralmente não se apresentam de forma consciente. Dessa forma, conhecimento manual, como é definido, refere-se ao que a mão conhece e que está escondido do cérebro (KRISTIANSEN e RASMUSSEN, 2014).

d) O papel conjunto dos diferentes tipos de imaginação. São elas: a imaginação descritiva, que busca imagens conhecidas para descrever algo que pode ser complexo na realidade; a imaginação criativa, que é responsável por criar algo totalmente novo e a imaginação desafiadora, que é a que desconstrói tudo que já existe, criando algo novo.

Nesse sentido, observando a realidade enfrentada pelas organizações e as dificuldades decorrentes do contexto atual, pode-se entender o método do LEGO Serious Play como recurso para torná-las melhores e mas eficientes (DE SOUZA, 2017). A Figura 1 aponta os três pontos-chave que são responsáveis pela geração de valor do LSP para empresas.

Figura 1: Como o Método LSP Cria Valor.

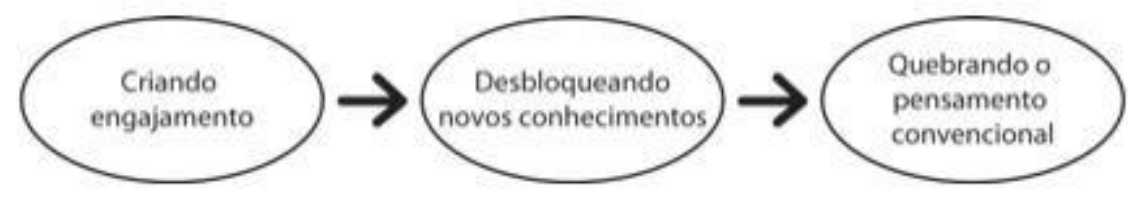

Fonte: Adaptado de (KRISTIANSEN E RASMUSSEN, 2014, p. 24). 
No que diz respeito a criar engajamento, o ponto de discussão se baseia nas reuniões 20/80. Essas recebem esse nome pelo fato de que muito comumente apenas $20 \%$ dos participantes falam $80 \%$ do tempo. Os $80 \%$ contribuem menos, explorando um percentual baixo de seu potencial. Essa situação ocorre, muitas vezes, pela presença de pessoas extrovertidas e, consequentemente, mais dominantes, que monopolizam a temática discutida. O objetivo do LEGO Serious Play é criar engajamento suficiente para que todos presentes participem igualmente, criando reuniões 100/100, ou seja, que as pessoas contribuam com o máximo de entrega e potencial (KRISTIANSEN e RASMUSSEN, 2015).

Desbloquear novos conhecimentos se refere às três vertentes defendidas por Kristiansen e Rasmussen (2015), que são: a) o conhecimento presente na sala é uma amostra das informações processadas e armazenadas diariamente pelo cérebro; b) entendimento do sistema é quando se trata da exploração a percepção do trabalho dentro de um sistema complexo, sendo necessário entender a identidade do grupo, que poderá ser dinâmica e imprevisível; e c) conexão com o propósito individual e da organização, fazendo que os colaboradores atinjam maior eficiência em suas funções a partir do momento que percebem sentido naquilo que estão desempenhando.

Quebrar o pensamento convencional vem do momento em que decidimos basicamente seguir pela linha de raciocínio mais fácil. Dessa forma, diz respeito ao pensar conforme os vícios de linhas de raciocínio e sempre andar por elas como se fossem os únicos meios possível. É nesse sentido que há o bloqueio de outros caminhos que podem desviar esses pensamentos, podendo ser extremamente válidos para enriquecer a ideia. 


\section{Metodologia de Pesquisa}

\subsection{Tipos de Pesquisa e Método Utilizado}

Para Fonseca (2002), methodos significa organização, e logos, pesquisa e investigação. Dessa forma, pode-se definir a metodologia como estudo da organização a ser percorrida para a realização de uma pesquisa. Diante dos objetivos de estudo deste artigo, entende-se que o tema de campo é pouco conhecido. Dessa forma, a pesquisa considerada mais adequada para obtenção de resultados foi a exploratória descritiva de natureza qualitativa, tratando-se de um estudo semiestruturado, não positivista.

A pesquisa descritiva expõe características de determinada população ou fenômeno, correlacionando variáveis e definindo sua natureza (VERGARA, 2006). Da mesma forma, a pesquisa exploratória, segundo Zikmund (2000), demonstra que os estudos provenientes desta são úteis para diagnosticar situações, explorar alternativas ou descobrir novas ideias. Nesse sentido, a aplicação conjunta desses dois métodos, exploratório e descritivo, objetivam a melhor definição do problema, proporcionando descrição dos comportamentos de fenômenos, intuição de de soluções, definição e classificação de fatos de variáveis.

$\mathrm{Na}$ abordagem qualitativa busca-se explicar o porquê das coisas, exprimindo recomendações do que deveria ser feito, mas não se relacionado com a quantificação de valores, uma vez que os dados analisados não serão métricos e podem seguir diferentes abordagens (GERHARDT e SILVEIRA, 2009). Além disso, não há a preocupação em comprovar hipóteses previamente estabelecidas.

Dentro do tema de campo, que é o serious play, decidiu-se pelo recorte do LEGO Serious Play, que é um dos métodos da abordagem. A escolha foi tomada pelo fato deste ser o método de serious play mais utilizado em workshops promovidos pelas organizações brasileiras atualmente. Nesse sentido, definiu-se como sujeitos da pesquisa os facilitadores do LSP por possuírem maior superfície 
de contato com as empresas e com todas as questões provenientes de sua relação com o serious play.

O período da pesquisa foi de 20 de maio a 10 de junho de 2019. Foram entrevistados sete facilitadores do método de diferentes estados, que aplicam o método em médias e grande empresas e que possuem experiência superior ao período de um ano. Lembra-se que tais profissionais possuem experiência mínima de um ano na aplicação do método em workshops contatados pelas empresas. Lembra-se que os entrevistados receberam códigos para garantir o anonimato e, por fins éticos, as identidades dos entrevistados serão preservadas.

\subsection{Procedimentos e Instrumentos de Coleta de Dados Utilizados no Estudo}

Para a coleta de dados, utilizou-se o formato de entrevista semiestruturada. Para Rosa e Arnoldi (2006), a entrevista é uma das técnicas de coleta de dados considerada racional em relação à conduta do pesquisador, que é previamente estabelecida para dirigir com eficácia o conhecimento extraído do entrevistado, de forma completa e no menor tempo possível. É nesse sentido que a técnica é confirmada como pertinente forma de obtenção de informações a respeito do objeto de pesquisa, permitindo mapear atitudes, valores e sentimentos inerentes ao comportamento do entrevistado.

Dessa forma, o objetivo principal era extrair dos entrevistados, de forma não tendenciosa, as perspectivas do LEGO Serious Play que poderiam facilitar demandas trazidas pelas empresas e, principalmente, confirmar ou não sua influência positiva para aspectos que facilitam o processo a gestão da mudança organizacional. $\mathrm{O}$ roteiro da entrevista continha quatro temáticas, que não foram conduzidas como em forma de pergunta e que não necessariamente foram seguidas em relação a cronologia, uma vez que o verdadeiro intuito era fazer com que o entrevistado sentisse que estava participando de uma conversa sem escopo, o que anexaria maior conforto e naturalidade a mesma. São elas:

- Me fale sobre os benefícios que você já percebeu nas empresas que usaram algum método de Serious Play. 
- Me fale se você já usou algum método de Serious Play com o objetivo de suportar algum tipo de mudança organizacional.

- Me fale sua percepção sobre as experiências de empresas com o Serious Play.

- Me fale sua percepção sobre a influência do método no comportamento dos colaboradores.

Pontua-se que as respostas foram gravadas em forma de áudio, com duração média de 30 minutos para cada entrevistado.

\subsection{Tratamento e Análise dos Dados Coletados para o Estudo}

As entrevistas e as informações fornecidas foram transcritas e analisadas individualmente para que, consequentemente, pudessem ser exploradas em conjunto, entendo raciocínios e percepções comuns. Os dados foram tratados de forma não estatística, ou seja, de forma qualitativa. A partir deste ponto, o referencial teórico foi utilizado para a análise dos dados da pesquisa.

\subsection{Limitações do Estudo}

A pesquisa aqui apresentada se limita ao universo apresentado pelos facilitadores do LEGO Serious Play e que, por isso, não representa a visão dos funcionários das organizações. Dessa forma, as respostas que foram obtidas através das entrevistas são traduções dos pensamentos, opiniões, percepções e, em alguns casos, "achismos" dos entrevistados, não se aplicando a qualquer outro cenário ou situações. 


\section{Apresentação e Análise dos Resultados}

\subsection{Perfil dos Entrevistados}

A fim de ratificar o compromisso ético assumido com os entrevistados, nenhum nome será revelado, sendo os facilitadores identificados por códigos. Lembra-se que a gravação das entrevistas foi permitida por todos os entrevistados e obedeceram ao critério de seleção proposto: facilitadores do método LEGO Serious Play que possuem experiência superior a um ano em sua aplicação. $\mathrm{Na}$ Tabela 2 é apresentado o perfil dos entrevistados.

Tabela 2: Perfil dos entrevistados facilitadores do LEGO Serious Play.

\begin{tabular}{|c|c|}
\hline Entrevistados & Tempo de experiência \\
\hline E1 & 2 anos \\
\hline E2 & 2 anos \\
\hline E3 & 3 anos \\
\hline E4 & 1 ano \\
\hline E5 & 4 anos \\
\hline E7 & 4 anos \\
\hline E8 & 3 anos \\
\hline
\end{tabular}

Fonte: A autora.

\subsection{Análise dos Dados}

Os dados colhidos durante as entrevistas foram frutos das experiências dos entrevistados como facilitadores durante a condução do método do LEGO Serious Play em diferentes empresas que possuíam diferentes demandas, que não necessariamente tinham clara associação com o processo de mudança organizacional. Após a realização das entrevistas, o conteúdo foi transcrito e analisado. Dessa forma, buscou-se identificar comportamentos, opiniões e traços comportamentais comuns aos entrevistados. Esses itens, por sua vez, foram 
categorizados e associados a fatores para facilitar a análise de dados diante do referencial teórico.

\section{Categoria 1: Integração entre Líder e Equipe}

O comprometimento gerado pela aplicação do método, assim como a real participação e presença dos líderes, foi um assunto pontuado em quatro das sete entrevistas realizadas. A partir das entrevistas, percebeu-se que a participação dos líderes e gestores acontece de forma não hierarquizada, ou seja, durante a aplicação do LSG, todos os colaboradores da empresa, independentemente do seu cargo ocupado, estão dispostos no mesmo nível hierárquico.

E3 relata como o método é conduzido para gerar a igualdade entre os participantes: "todo mundo começa com o mesmo número de peças e são formados grupos ecléticos e alinhamos habilidades e desafios para que todos entreguem de uma forma consistente". O entrevistado ainda conta que é depois desses primeiros estágios que o comprometimento é incitado: “é após colocarmos (os participantes) no flow, que o comprometimento e a cumplicidade são trabalhado". E2 também corrobora com a visão de quebra da hierarquia: “diferentes níveis hierárquicos não importam porque o método todo mundo é igual", assim como E5: "é todo mundo igual, sem hierarquia, todo mundo do mesmo nível mesmo".

E1 explica como o método pode despertar um vínculo mais profundo entre colaboradores e gestores: "a partir do momento que você conhece de verdade a pessoa que está do seu lado... você gera um compromisso pessoal com a empresa e isso vai além do profissional, é mais forte". Da mesma forma E4 "a construção conjunta de soluções faz com que o chefe perceba quem é quem na equipe, ele se envolve naquele processo como ser humano e não como chefe (...) a liderança se torna mais clara para ele à medida que ele conhece quem está liderando". 


\section{Categoria 2: Engajamento dos Colaboradores}

O envolvimento, a integração e o engajamento dos colaboradores com os demais e com as organizações que são percebidos durante e após a aplicação do método LEGO Serious Play foram questões abordadas de forma unânime pelos entrevistados.

E1 conta que "todo mundo participa, conta sua história, escuta a história do outro e isso vai criando um envolvimento coletivo". O entrevistado também explica as duas diferentes inteligências que são trabalhadas durante a aplicação do método: “o LEGO trabalha a inteligência intrapessoal e a interpessoal. A primeira é você com você mesmo, o seu autoconhecimento. A segundo é você com os outros. Você quer ver no que o outro pensou e isso ajuda muito nas mudanças que vão precisar ser feitas". Além disso, ele pontua a necessidade do mesmo grau de envolvimento dos participantes para o sucesso da aplicação do LSP: "se você não fizer, o resultado do grupo é comprometido, por isso que é necessário criar um espaço de confiança entre a equipe, que fica visivelmente mais envolvida com o desafio".

E2 explica o processo de autoconhecimento que também é observado durante a aplicação do método: "a pessoa consegue se reconhecer no modelo que ela mesma fez, ela se reconhece e reconhece o porquê de estar ali, isso cria um sentimento de pertencimento". Nesse sentido, ela complementa "a pessoa consegue levar sua perspectiva pessoal para as construções coletivas, então ela consegue enxergar a opinião dela naquela solução, quanto maior for o alinhamento, mas insights surgem".

E3 pontua a importância do método para causar a clareza da identidade pessoal e profissional do colaborador: "é possível mapear a identidade pessoal e profissional de cada pessoa e os papéis de cada um ficam muito claros. Você enxerga sua importância e sabe qual é seu papel e como contribuir". Ela ainda fala sobre o nível de profundidade que o método é capaz de chegar: "quanto mais confiança as pessoas sentirem, maior é o nível de entrega (...) algumas chegam a se emocionar, o envolvimento é realmente a nível emocional”.

Para E4 e E7 defendem que o envolvimento percebido é fruto da motivação, E4 diz: 
Quando a pessoa se dá conta que a resposta que ela tanto queria estava na mente dela o tempo todo, ela se sente empoderada, motivada. Ela olha aquilo e entende que é possível fazer aquilo e o engajamento acontece. E ao se sentirem parte da solução, elas se motivam, elas querem que as ideias sejam colocadas em prática, elas se envolvem.

Nesse sentido, E6 ajuda a complementar tal visão dizendo "eles sentem orgulho do que construíram e isso gera autoconfiança".

\section{Categoria 3: Comunicação}

Notou-se que a comunicação é um dos fatores mais discutidos como importantes diante da aplicação do método. O conceito de 100/100, modelo que diz respeito a $100 \%$ de participação de todos os envolvidos em uma reunião, foi falado por 6 dos 7 entrevistados, o que corrobora a relevância do tema.

Para E1 e E2, um dos principais benefícios do método é a comunicação: "com certeza é um benefício as pessoas poderem se colocar de uma forma mais verdadeira com o aumento da possibilidade da comunicação" e completa "gera um espaço de reflexão, de compartilhamento, abre espaço para quem normalmente não fala nas reuniões e não tem espaço para falar as boas ideias”. Para E2 a comunicação é uma das principais demandas trazidas pelos contratantes: "os gestores muitas vezes não querem ouvir, mas sabem que é preciso. E, no LEGO, todo mundo tem voz e todo mundo tem que escutar".

E3, da mesma forma, comenta a dificuldade em escutar de algumas empresas: "elas não querem escutar um feedback, não estão prontas para saber a opinião dos colaboradores, mas faz parte do processo, para dar certo é preciso escutar e isso não é fácil”.

E4 defende a comunicação ao dizer: "ele facilita muito a comunicação porque as pessoas conseguem ser mais naturais quando elas respondem uma pergunta (...) diante do modelo as pessoas não estão diretamente do problema, e sim do modelo, então falar fica mais fácil". A entrevistada defende que as respostas obtidas pelo LEGO Serious Play são mais sinceras e livre de dissonâncias: 
Outra coisa é quando você é desafiado a responder uma pergunta para o modelo, esse processo estimula respostas emocionais, inconscientes e racionais. É a mente que fala naquele momento e passa para as mãos fazerem, e a mente não mente. As pessoas vão fazendo o modelo e vão se dando conta e pensam 'eu não tinha pensado nisso'. Mas, na verdade, tinha. A resposta estava lá o tempo todo.

Nesse sentido, E4 afirma como a contratação de terceiros podem ser desnecessárias:

Muitas empresas ainda contratam consultores, que são pessoas que estão de fora e não conhecem o problema, sendo que não usam a própria equipe para pensar naquilo. Eu sempre afirmo que as competências e as habilidades que as empresas precisam para resolver os problemas estão na própria empresa.

No mesmo sentido, E7 pontua "é muito agregador porque a sua opinião ajuda a construir a opinião do outro e todo mundo se orgulha daquilo que construíram juntos".

E5 pontua o sentimento despertado após a fala "por ser algo que as pessoas são obrigadas a falar, aquela pessoa que é mais fechada consegue se expressar, a partir do momento que aquilo é expressado em um ambiente externo, a ideia fica alheia a pessoa e é mais fácil". Por sua vez, E6 explica como isso é possível "a questão de você provocar um ambiente onde existe mais fluidez de pensamento permite trazer a tona um pensamento mais verdadeiro".

\section{Categoria 4: Identificação de Problemas}

Cinco dos sete entrevistados defenderam que o LEGO Serious Play ajuda na identificação de problemas, assim como a definição de planos de ação. Nota-se que não são os facilitadores que decifram as problemáticas existentes nas empresas, uma vez que o método propõe que esse seja um resultado natural do próprio processo.

E1 defende o desconhecimento dos gestores sobre as reais causas dos problemas: "o cliente acredita que as vezes o problema é uma coisa, mas na verdade é outra. Algumas vezes ele quer tratar a consequência achando que é a causa e com o método a gente consegue enxergar onde está errado". Ela completa dizendo 
"podemos mapear e resolver um problema, a gente consegue responder e muito do que a gente faz durante os workshops poderiam ser utilizados pelas empresas”.

E2, sob a mesma vertente, explica os benefícios resolutivos do método:

Eu não vendo LEGO, eu vendo uma solução, entrega, diagnóstico. Eu não vendo o lúdico. LEGO não é brinquedo, não é só fun, a metodologia é muito bem estruturada. Mas é necessário mapear isso, o que é difícil. Mapear, transcrever, analisar e dar solução para um problema real.

E3 pontua a valorização das opiniões dos colaboradores para o atingimento do diagnóstico “onde eu estou? Pra onde eu vou? Ouvir as diferentes perspectivas é entender em que momento você está, isso enriquece o plano de ação de forma eficiente". Ela ainda esclarece: "primeiro é preciso enxergar o momento que a empresa está vivendo, nós perguntamos "se vocês pudessem enxergar uma fotografia agora da empresa, o que você iria construir?”. Ele vai contando a história do modelo e vai entendendo as percepções do 3D. As mãos deles constroem o que ele diria e o que ele não diria e a leitura vai acontecendo. E o diagnóstico vai acontecendo e ficando claro. E é um diagnóstico puro porque explora diferentes dimensões, racional, emocional e inconsciente.

E6, nesse sentido, diz: “o LEGO faz vir a tona uma série de problema que não são visíveis e o mapeamento dessa situação faz com que as pessoas ajam de forma mais pontual no trabalho". E5 defende a incapacidade da empresa de gerar soluções em alguns casos: "as empresas não têm todas as respostas, muitas vezes as pessoas não se dão conta" e completa com uma de suas experiências "um grupo totalmente desacreditado, que não sabia onde era o problema, conseguiu deixar o workshop com 18 planos de ação diferentes".

\section{Achados da Pesquisa}

A partir das quatro categorias subdivididas, foram elaborados três achados, fruto da conversa do referencial teórico da gestão da mudança com os dados provenientes das entrevistas. 
Achado 1: O Serious Play facilita a gestão da mudança por desenvolver o comprometimento e participação ativa do líder e o envolvimento ativo dos colaboradores.

Observou-se que sete dos sete entrevistados criaram com conexão entre a aplicação do método do LEGO Serious Play em empresas e o engajamento de seus colaboradores, que desperta comprometimento, participação e envolvimento. Sabese que Bakker e Leiter (2010), definem o engajamento no trabalho como algo positivo, relacionando-se com a satisfação baseada em um alto nível de energia e forte identificação com o próprio trabalho. Os autores defendem que uma equipe de trabalhadores engajados pode influenciar no comportamento e desempenho do colaborador de forma individual. Dessa forma, o engajamento é sugerido como benéfico para as empresas e para empregados, uma vez que há uma relação direta entre o comportamento do colaborador e seu desempenho no trabalho, o que também os deixam mais abertos a novas experiências (BAKKER et al., 2012).

Nesse sentido, para que seja possível a criação de um ambiente propício a mudança é necessária que haja engajamento, comprometimento e envolvimento de todos os níveis hierárquicos da organização, sendo preciso que cada um dos colaboradores esteja engajado individualmente para o sucesso do processo de mudança organizacional (SILVA e VERGARA, 2000).

Achado 2: O Serious Play facilita a gestão da mudança por melhorar a comunicação efetiva na organização.

Notou-se que a grande maioria dos entrevistados, seis de sete facilitadores, pontuaram a abertura da comunicação como fator determinante para o método do LEGO Serious Play, assim sendo considerado um dos seus maiores benefícios. Sabe-se que a comunicação é um dos elementos mais importantes no contexto de processo da mudança organizacional. Além de ser um instrumento responsável por anunciar, divulgar e explicar as transformações, a comunicação também prepara as pessoas para possíveis consequências positivas e negativas que elas podem desenvolver. Da mesma forma, quando bem trabalhada, consegue elevar a 
compressão e o comprometimento com o processo de mudança, assim como diminuiu a má interpretação de seu significado, a resistência à inovação, sustentar o processo de mudança; obter feedback sobre percepções, opiniões e crenças dos membros da organização e preparar as pessoas para as alterações nas suas atitudes e comportamentos (SILVA e VERGARA, 2000).

Achado 3: O Serious Play facilita a gestão da mudança por diagnostica problemas organizacionais.

Por fim, notou-se que grande parte dos entrevistados, cinco de sete, elencaram o diagnóstico do problema como um dos principais benefícios vivenciados pelas empresas que experimentam o LEGO Serious Play.

O diagnóstico de problemas é um dos principais fatores que contribuem para o processo de mudança organizacional e pode ser concebido a partir de duas óticas: a do consultor, que é representada pelos facilitadores do método do LEGO e do contratante, que é representado pelas empresas. Para o consultor o diagnóstico possibilita compreender a natureza do problema, uma vez que permitirá a concepção e a elaboração de um projeto de intervenção. Para o contratante, os conhecimentos provenientes do diagnóstico servem de base para a tomada de decisão. Dessa forma, as razões da importância do diagnóstico diante deste processo é baseada em dois aspectos: a) a compreensão da real natureza do problema e a partir disso chegar ao melhor entendimento dos anseios coletivos associados a ele; e b) identificar quais são as forças que deverão ser mobilizadas para uma mudança organizacional significativa (CZANDER e EISOLD, 2003). 


\section{Conclusão}

O objetivo deste artigo foi responder à pergunta de pesquisa: como o Serious Play pode ajudar no processo de facilitação da mudança organizacional? Como possível resposta, foram identificados três achados a partir da análise dos dados das entrevistas realizadas com facilitadores do LEGO Serious Play.

No entanto, notou-se que duas características que são associadas ao êxito do processo de mudança organizacional, de acordo com A American Productivity Quality Center (1997), não foram observadas no conteúdo extraído das entrevistas, que são: a mudança fundamental na cultura e o alinhamento dos recursos humanos com as metas e objetivos da organização. Nenhum dos entrevistados mencionou ligação direta com a mudança fundamental da cultura, defendendo em grande parte das vezes que não há um caráter disruptivo que leve a transformação da cultura após a aplicação do método. Em relação ao alinhamento de recursos humanos com as metas e objetivos da organização, a ligação entre o LSP e a característica não foi defendida claramente, sendo muitas vezes resumida como alinhamento de equipe para a sinergia de metas propostas pela empresa. Tal dado extraído da pesquisa não foi considerado suficiente para qualquer tipo de conclusão ou associação.

Da mesma forma, notou-se que o mapeamento de papéis desempenhados por cada colaborador é um dos temas que merece maior exploração, uma vez que só foi defendido por apenas um dos sete entrevistados, mas que mantém clara associação com a liderança frente ao processo de mudança organizacional, que também é demonstrado pela American Productivity Quality Center (1997).

Após a elaboração das três proposições apresentadas é sugerido que pesquisas de caráter quantitativo seja realizadas a fim de obter análises a partir de amostras estatísticas. Também é sugerido que futuras pesquisas de caráter qualitativo sejam realizadas com outros métodos que se baseiam na abordagem do serious play, que não somente o LEGO Serious Play, para que mais dados sejam passíveis de análise. Dessa forma, será possível elaborar uma investigação mais 
aprofundada e apurada, sendo esta traduzidas em números, fazendo com que seja possível que o assunto seja tema de demais trabalhos acadêmicos.

Nota-se que a associação entre o serious play e o processo de mudança organizacional abre margem para diversos campos de pesquisa que poderão ser explorados a fim de fortalecer a bibliografia sobre o tema, que ainda é consideravelmente defasado. Dessa forma, considera-se que estudos acadêmicos são necessários, bem-vindos e altamente demandados pelo anseio evidente de mudança constante na sociedade. 


\section{Referências Bibliográficas}

ASSOCIADOS. ABStartups. 2018. Disponível em:

<https://abstartups.com.br/associados/>. Acesso em: 20 mai. 2019.

AMERICAN PRODUCTIVITY QUALITY CENTER (APCQ) White Paper. Organizational Change: Managing the Human Side. Disponível em: <www.apcq.org/free/whitepapers/orgchange/>. Acesso em: 10 jun. 2019.

ANDERSON, D., ANDERSON, L. S. Beyond Change Management: advanced strategic for today's transformational leaders. San Francisco: Jossey-Bass, 2001.

ARGYRIS, C., \& SCHON, D. A. Organizational Learning II: Theory. Method, and, 1996.

BAKKER, A. B., \& LEITER, M. P. Where to go from here: integration and future research on work engagement. In: BAKKER, A. B.; LEITER, M. P. (Orgs.), Work Engagement: a handbook of essential theory and research. New York: Psychology Press, 2010.

BAKKER, A. B. et al. Work engagement, performance, and active learning: the role of conscientiousness. Journal of Vocational Behavior, 80, 555-564.

BENNETT, N., LEMOINE, G.J. What VUCA Really Means for You. Harv. Bus. Rev. 2014, 92, 1-2.

BLANCHARD, K. Liderança de Alto Nível: como criar e liderar organizações de alto desempenho. Bookman Editora, 2009.

BORTOLOTTI, L. Delusions and Other Irrational Beliefs. Oxford University Press, 2010.

BOVEY, Wayne H.; HEDE, A. Resistance to Organisational Change: the role of defense mechanisms. Journal of Managerial Psychology, v. 16, n. 7, p. 534-548, 2001.

BRESSAN, C. L. Mudança Organizacional: uma visão gerencial. Seminário de gestão de negócios, 1, 2004. 
CHIAVENATO I. Pessoas, Organizações e Sistemas. São Paulo. Atlas, 1996.

CHIAVENATO, I. Administração Geral e Pública: provas e concursos. Editora Manole, 2016.

CSIKSZENTMIHALYI. The Domain of Creativity, 1990.

CZANDER, W.; EISOLD, K. Psychoanalytic perspectives on organizational consulting: Transference and counter-transference. Human Relations, 2003.

DEMPSEY, M. et al. Serious Play as a Method for Process Design. In: GRABOT, B. et al. (Eds.), Advances in Production Management Systems. Innovative and Knowledge-Based Production Management in a Global-Local World: Springer Berlin Heidelberg, 2014.

DO CARMO REIS, M. Comunicação e Mudança Organizacional: uma interlocução instrumental e constitutiva. Organicom, 1(1), 36-53, 2004.

DO NASCIMENTO FREIRE, D. A.; Resistência à Mudança Organizacional: perspectiva valorativa e organizacional. Psico, 45 (4), 513-523, 2014.

DUCK, S. Relating to Others 2/e. McGraw-Hill Education (UK), (1999).

FONSECA J. J. S. Metodologia da Pesquisa Científica (2002).

FRIEDMAN, T.L. O Mundo é Plano: Uma breve história do séc. XXI. Rio de Janeiro, Objetivo, (2005).

Gerhardt, T. E., \& Silveira, D. T. (2009). Métodos de pesquisa. Plageder.

HANSEN, P.K., MABOGUNJE, A., HAASE, L.M.: Get a Grip on Sense: Making and Exploration Dealing with Complexity through Serious Play. In: Sun, H., Jiao, R., Xie, M. (eds.) IEEE International Conference on Industrial Engineering and Engineering Management, pp. 1593-1597. IEEE Press (2009).

HAYES, J. The Theory and Practice of Change Management. New York: Palgrave, (2002). 
HORNEY, N.; O'SHEA, T. Focused, Fast \& Flexible: Creating agility advantage in a VUCA world. Oceanside, CA: Indie Books International, 2015.

HUIZINGA, J. Homo Ludens: o jogo como elemento da cultura. v. 4. Editora da Universidade de S. Paulo. São Paulo: Editora Perspectiva, 1971.

OS 5 unicórnios brasileiros de 2018 e o que esperar para as startups em 2019. It Mídia. 2018. Disponível em <https://itmidia.com/os-5-unicornios-brasileiros-de2018-e-o-que-esperar-para-as-startups-em-2019/>. Acesso em: 20 mai. 2019.

JOE, T. et al. Managing Innovation: integrating technological, market and organizational change. John Wiley \& Sons, 2005.

KOTTER, J. P. Leading Change: Why transformation efforts fail, 1995.

KOTTER, J. P. What Leaders Really Do. Harvard Business Review. May-June, 37-60, 1990.

KRISTIANSEN, P., \& RASMUSSEN, R. Building a Better Business Using the Serious Play Method. New York, NY: Wile, 2014.

KRISTIANSEN, P. et al. Articulation of Tacit and Complex Knowledge. Zürich: Eidgenössische Technische Hochschule, 2009.

KUEPERS W. Inter-Play(ing): Embodied and Relational Possibilities of Serious Play at Work. Journal of Organizational Change Management, Emerald, 2017.

LEWIN, K.; GOLD, M. Group Decision and Social Change. The Complet Social Scientist: A Kurt Lewin Reader. American Psychologial Association, Washington, DC, 1999.

LIMA, S. M., \& BRESSAN, C. L. Mudança Organizacional: uma introdução. Mudança organizacional: teoria e gestão. Rio de Janeiro: FGV, 2003.

MAGALDI, S., NETO, J. S. Gestão do amanhã: tudo o que você precisa saber sobre gestão, inovação e liderança para vencer na $4^{a}$ revolução industrial. São Paulo: Gente, 2018. 
MARQUES, A. L. Resistência à Mudança e Suas Relações com o Comprometimento, qualidade de vida e estresse no trabalho: Estudo da reforma gerencial do governo de Minas Gerais. UFMG, Belo Horizonte, 2012.

MARQUES, A. L. et al. Validando um Instrumento de Medida de Resistência à Mudança. Encontro da Associação Nacional de Pós-Graduação e Pesquisa em Administração, 29, 205, 2005.

MARQUES, A. L. et al. Resistência à Mudança Organizacional e Stress no Trabalho. Revista de Administração FACES Journal, 15 (1), 2016.

NALDER D., SHAW R., WALTON A. Discontinuous Change: leading organizational transformation. San Francisco: Jossey-Bass, 81, 1995.

OREG, S. Personality, Context, and Resistance to Organizational Change. European journal of work and organizational psychology, 15 (1), 73-101, 2006.

PIDERIT, S. K. Rethinking Resistance and Recognizing Ambivalence: A multidimensional view of attitudes toward an organizational change. Academy of management review, 25 (4), 783-794, 2000.

RIEBER, L. P. et al. The Value of Serious Play. Educational Technology, 38 (6), 29-37, 1998.

RIES E. The Lean Startup: How constant innovation creates radically successful businesses. London: Penguin Group, 2011.

ROBBINS, S. P. Administração: Mudanças e Perspectivas. São Paulo: Editora Saraiva, 2003.

ROOS, J. et al. Playing Seriously With Strategy. Long Range Planning, 37 (6), 549-568, 2004.

ROSA, Maria Virgínia de Figueiredo Pereira do Couto; ARNOLDI, Marlene Aparecida Gonzalez Colombo. A entrevista na pesquisa qualitativa: mecanismos para a validação dos resultados. Belo Horizonte: Autêntica Editora, 2006.

SILVA, J. R. G.; Sentimentos, subjetividade e supostas resistências à mudança organizacional. Revista de Administração de Empresas, 43 (3), 10-21, 2003. 
SILVA, L. M. A Essencialidade do Direito de Acesso à Internet Sob a Perspectiva das Mudanças e Rupturas Geradas pela Quarta Revolução Industrial. Vitória: FDV, 2018.

STEELE, F. Making and Managing High-Quality Workplaces: An organizational Ecology. New York: Teachers College Press, 1986.

VERGARA, S. C. Projetos e Relatórios de Pesquisa. São Paulo: Atlas, 2006.

WHITTINGTON, R. Learning More from Failure: Practice and process. Organization Studies, 27(12), 1903-1906, 2006.

WOOD Jr, T. et al. Vencendo a Crise: mudança organizacional na Rhodia Farma. Revista de Administração de Empresas, 34 (5), 62-79. (1994).

ZIKMUND, W. G. Business Research Methods. 6, 2000. 